\title{
Análise da evasão no ProJovem Urbano: uma abordagem através do Modelo de Regressão Logística Multinível
}

\author{
Tufi Machado Soares* \\ Maria Eugénia Ferrão** \\ Cláudio de Albuquerque Marques ${ }^{* * *}$
}

\section{Resumo}

Apesar das grandes conquistas verificadas no Brasil nas últimas décadas em Educação, o sistema educativo brasileiro ainda apresenta características estruturais que constituem obstáculo ao seu desenvolvimento social e econômico: as elevadas taxas de retenção e abandono escolar. Como consequência, o nivel de instrução da população em idade ativa é baixo. Sob a responsabilidade da Presidência da República, foi desenhado o programa ProJovem Urbano, cuja finalidade prioritária é promover a inclusão social dos jovens brasileiros de 18 a 29 anos que, apesar de alfabetizados, não concluiram o Ensino Fundamental. Não obstante o programa atrair o interesse de elevado número de jovens, a desistência e evasão que se verificam ao longo do programa são muito elevadas.

Este trabalho tem como principal objetivo identificar os grupos de maior incidência da evasão, tendo como propósito apoiar a implementação de medidas que a reduzam. Nestes termos, usando um modelo logístico multinivel, são exploradas as seguintes características da população abrangida: sexo, idade, raça-cor, última série frequentada, nível de conhecimento em Matemática e Língua Portuguesa à entrada no Programa, nível socioeconômico e a região metropolitana.

Os resultados sugerem que os grupos de maior incidência da evasão são definidos pelas variáveis sexo, idade e região.

Palavras-chave: ProJovem. Avaliação. Indicadores de performance. Evasão. Inclusão social. Política pública. Modelo de Resposta ao Item. Modelo Logístico Multinivel.

* Professor do Departamento de Estatística, Universidade Federal de Juiz de Fora (UFJF); Coordenador de Pesquisa do Centro de Políticas Públicas e Avaliação da Educação (CAEd); Professor do Programa de Pós-Graduação em Educação, UFJF.

** Professora de Estatística, Universidade da Beira Interior (Portugal); Investigadora do Centro de Matemática Aplicada à Previsão e Decisão Econômica (CEMAPRE), Centro de Investigação do Instituto Superior de Economia e Gestão, Universidade Técnica de Lisboa.

**** Professor do Departamento de Fundamentos da Educação, Universidade Federal do Ceará (UFC); Coordenador do ProJovem Urbano para os Estados do Ceará, Piauí e Maranhão; Professor do Programa de Pós-Graduação em Educação, UFC. 


\section{Analysis of the Urban 'ProJovem' evasion: an approach through the Multilevel Logistic Regression Model}

\section{Abstract}

Despite the great achievements recorded in Brazilian Education in recent decades, the Brazilian system still has structured characteristics that hamper its socioeconomic development: the high rates of retention and school evasion. As a result, the educational level of the working age population is low. Under the responsibility of the Presidency of the Republic, the Urban ProJovem was designed: its primary goal is to promote the social inclusion of 18-29-year-old Brazilians who, even literate, have not completed Primary School. Although the Program attracted the interest of many young people, the withdrawal and evasion were still very high.

This study aims to identify the main groups of higher incidence of evasion, with the aim to implement measures to reduce it. Thus, using a multilevel logistic approach, the following characteristics are taken into consideration: sex, age, race, color, last grade attended, levels of knowledge in Math and Portuguese at the entrance to the Program, socioeconomic level and the metropolitan area. The results suggest that the groups with higher incidence of evasion were defined by gender, sex, age and region.

Keywords: ProJovem. Evaluation. Perfomance indicators. Evasion. Social inclusion. Public policy. Evasion. Inclusion. IRT Model. Logistic Multilevel Model.

\section{Análisis de la Evasión en el ProJoven Urbano: Un Abordaje a través del Modelo de Regresión Logística Multinivel Resumen}

A pesar de las grandes conquistas verificadas en Brasil durante las últimas décadas en el área de la Educación, el sistema educativo brasileño todavía presenta características estructurales que son obstáculo para su desarrollo social y económico: las altas tasas de retención y abandono escolar. Como consecuencia de ello, el nivel de instrucción de la población en edad activa es bajo. Con la responsabilidad de la Presidencia de la República, se proyectó el programa Projoven Urbano, cuya finalidad es promover la inclusión social de los jóvenes brasileños de 18 a 29 años que, a pesar de alfabetizados, no concluyeron la Escuela Primaria. Aunque el programa atrae el interés de gran número de jóvenes, el abandono y la evasión que se verifican a lo largo del programa son muy altos. Este trabajo tiene como principal objetivo identificar los grupos de mayor incidencia de la evasión, para poder apoyar la implementación de medidas que 
la reduzcan. En estos términos, se usa un modelo logístico multinivel, se analizan las siguientes características de la población alcanzada: sexo, edad, etnia-color, último grado o año cursado, nivel de conocimiento en Matemáticas y Lengua Portuguesa al entrar en el Programa, nivel socioeconómico y la región metropolitana.

Los resultados sugieren que los grupos de mayor incidencia de la evasión son definidos por las variables de sexo, edad y región.

Palabras-clave: ProJoven. Evaluación. Indicadores de Performance. Evasión. Inclusión Social. Política Pública. Modelo de Respuesta al Ítem. Modelo Logístico Multinivel.

\section{Introdução}

Ao longo dos últimos anos verificou-se grande desenvolvimento na educação e qualificação da população brasileira, em particular no que se refere ao acesso das crianças e jovens à educação. Segundo a Pesquisa Nacional por Amostra Domiciliar (PNAD) (IBGE, 2008), a taxa de escolarização da população em idade escolar (6-14) foi 97,5\% e na faixa etária 15-17 de 84\%. As estatísticas do fluxo escolar também revelam uma melhoria considerável. A comparação da situação antes da publicação e implementação da Lei de Diretrizes e Bases da Educação, Lei no 9.394 (BRASIL, 1996), com a atualidade permite verificar as mudanças. A LDB (BRASIL, 1996) incentivou 0 desenvolvimento e implementação de propostas de correção do fluxo escolar tais como: classes de aceleração da aprendizagem, o regime de ciclos e a promoção automática, entre outras. Em 1992, a taxa de repetência média da $1^{\text {a à }} 4^{\text {a }}$ série do Ensino Fundamental foi $35 \%$, e a da $5^{\text {a }}$ à $8^{a}$ série do Ensino Fundamental foi $30 \%$. A maior

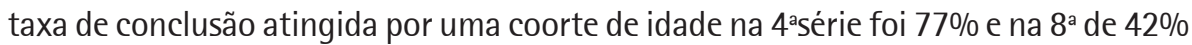
(KLEIN, 2006). 0 efeito das medidas decorrentes da LDB (BRASIL, 1996) é parcialmente visivel através das estatísticas reportadas a 2003, por exemplo. Concretamente, a taxa de repetência média da $1^{\mathrm{a}}$ à $4^{\mathrm{a}}$ série do Ensino Fundamental foi 19,8\% e da $5^{a}$ à $8^{a}$ série do Ensino Fundamental de 18,5\%; a maior taxa de conclusão observada

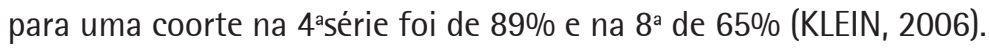

Todavia, a distribuição da população adulta (idade 25-64) por nivel educacional revela a necessidade de medidas adicionais para dotar a população ativa com os níveis de educação e qualificação necessários ao desenvolvimento humano, social e econômico do pais. Note-se, por exemplo, que enquanto 68\% da população em idade ativa no Chile frequentaram algum nível de ensino acima do Ensino Fundamental, a percentagem é apenas de 39\% no Brasil. Essa percentagem nos paises da Organização para Cooperação e Desenvolvimento Econômico (OCDE) é, em média, de 72\%, semelhante à observada na região dos 19 paises da União Europeia (UE19, antes da última ampliação) e de 89\% nos EUA (OECD, 2010, table A1.1a).

A comparação da percentagem da população em idade 25-34 que frequentou algum nível de ensino até 0 ensino secundário, reforça 0 anteriormente exposto. $A$ 
percentagem referente ao Brasil é $50 \%$, a média nos países da OCDE é $80 \%$, nos paises UE19 82\%, no Chile 85\% ,e nos EUA 88\% (OCDE, 2010, table A1.2a).

Tabela 1. Distribuição da população (25-64) por mais elevado nível de ensino frequentado.

\begin{tabular}{c|c|c|c}
\hline & $\begin{array}{c}\text { Até Ens.Secundário } \\
{[1]}\end{array}$ & $\begin{array}{c}\text { Ensino Secundário } \\
{[2]}\end{array}$ & $\begin{array}{c}\text { Ensino Superior } \\
{[3]}\end{array}$ \\
\hline OECD (média) & 29 & 44 & 28 \\
\hline EU19 (média) & 28 & 47 & 25 \\
\hline Brasil & 61 & 28 & 11 \\
\hline Chile & 32 & 44 & 24 \\
\hline México & 67 & 17 & 16 \\
\hline EUA & 11 & 48 & 41 \\
\hline
\end{tabular}

Fonte: Adaptado de OECD (2010, table A1.1a).

0 ProJovem Urbano (2010) é um programa da responsabilidade da Secretaria Geral da Presidência da República que visa a promover a inclusão social dos jovens brasileiros com idade compreendida entre 18 e 29 anos, que saibam ler e escrever e não tenham concluído o Ensino Fundamental. Concretamente, as medidas visam a elevação da escolaridade através da conclusão do Ensino Fundamental; a qualificação profissional e o desenvolvimento de ações comunitárias com exercício da cidadania, a promoção de experiência de atuação social na comunidade (BRASIL, 2008c). Os objectivos específicos são os seguintes: a reinserção dos jovens no processo de escolarização; a identificação de oportunidades potenciais de trabalho e a capacitação dos jovens para o mundo do trabalho; a participação dos jovens em acções coletivas de interesse público; a inclusão digital como instrumento de inserção produtiva e de comunicação; a ampliação do acesso dos jovens à cultura (BRASIL, 2008b; PROJOVEM URBANO, 2010).

De acordo com o regulamento do programa ProJovem Urbano (BRASIL, 2008b), o programa é implementado gradativamente nos Estados, no Distrito Federal e nos Municípios que a ele aderirem, mediante aceitação das condições estabelecidas no Decreto n ${ }^{0} 6.628$ (BRASIL, 2008a) e assinatura de termo de adesão a ser definido pela Secretaria-Geral da Presidência da República. No que se refere ao estabelecimento das respectivas metas por Estado, Municipios e no Distrito Federal, o mesmo Decreto institui que elas são proporcionais à população estimada que possua o perfil do jovem em condições de participação.

A avaliação do Programa ProJovem, 1afase, instituido pela Lei no 11.129 (BRASIL, 2005), aponta a desistência e evasão dos participantes como um dos principais obstáculos ao sucesso pleno do programa. Em particular, o ProJovem (BRASIL, 2008d) registra que, entre os jovens matriculados no ProJovem, 57\% desistiram ou se evadiram². 0

2 Evadidos são os jovens que frequentaram o Programa, chegando mesmo a completar alguma de suas etapas mas que não permaneceram no Programa até à sua finalização. 
mesmo relatório indica que a desistência é de 37\% e a evasão de 20\%. De acordo com o estudo efetuado, os motivos enunciados para a elevada percentagem da evasão são 0 atraso no pagamento das bolsas, a falta ou insuficiência das aulas de informática (BRASIL, 2008d), violência nas proximidades do núcleo, falta de recursos financeiros para transporte, impossibilidade de trabalhar e frequentar as aulas e a distância de casa ao núcleo (BRASIL, 2008d). 0 relatório de avaliação também reporta que a aferição da aprendizagem efetuada pelos jovens que concluem o Programa na componente formativa evidencia que o seu nivel de proficiência (à saída) "é similar à média dos egressos das escolas municipais de Ensino Fundamenal e o percentual de jovens que ficam abaixo da média no EFNE é baixo" (BRASIL, 2008d, p. 116).

Na sequência da avaliação efetuada do programa ProJovem, a Lei no 11.692 (BRASIL, 2008c), estabelece novo enquadramento para o Programa, nomeadamente criando diferentes modalidades para atender aos diferentes perfis dos alunos, entre as quais se inclui o ProJovem Urbano, e estipula como obrigatória a inclusão de módulos de informática, para além de outras medidas que contribuem para a melhoria da qualidade dos cursos oferecidos.

Este artigo tem três objetivos principais: o primeiro é o de quantificar a desistência e evasão com base no $1^{\circ}$ coorte do ProJovem - Urbano (2010); o segundo é o de identificar quais são as principais variáveis individuais que estão associadas à evasão; 0 terceiro é o de mostrar que o nível de conhecimento dos alunos que concluem o programa aumenta, independentemente da sua certificação final. Na sequência da avaliação do programa anterior, estabelecemos como hipóteses de trabalho que as variáveis associadas à maior incidência da evasão são variáveis sociodemográficas, tais como idade, sexo, raça/cor, condição econômica; e as de trajetória escolar, tais como última série frequentada e nivel de conhecimento à entrada no programa. Adicionalmente, pareceu-nos relevante testar se a evasão se diferencia por região.

Na próxima seção, apresentam-se aspectos metodológicos relacionados com a caracterização sociodemográfica do $1{ }^{\circ} \mathrm{C}$ corte da população abrangida no ProJovem Urbano, com os instrumentos e escalas de desempenho de Língua Portuguesa e de Matemática e com o modelo estatístico usado na modelagem da evasão. Na terceira seção, apresentam-se os resultados e, finalmente, a discussão/conclusão.

\section{Metodologia}

\section{Definição e caracterização sociodemográfica da população}

Para a primeira entrada do ProJovem Urbano se inscreveram 95037; desses 18344 (19.3\%) não chegaram a receber nenhum auxílio financeiro (isto é, a bolsa estipulada pela lei) e, portanto, pode-se admitir que não chegaram a entrar no programa. Dos 76693

3 Exame Final Nacional Externo ao qual foram submetidos os jovens concluintes do ProJovem (BRASIL, 2008d, p. 73). 
restantes, que receberam pelo menos um auxílio, 29551 não se submeteram a qualquer avaliação em Matemática ou Língua Portuguesa. Esses jovens, os que não receberam nenhum auxílio financeiro e/ou nem participaram de qualquer das avaliações, são considerados desistentes do programa. Nestes termos, os restantes 47142 alunos (49.6\% do total de inscritos) constituem a população que efetivamente participou no Programa. 0 gráfico 1 mostra a distribuição dos indivíduos pelo número de bolsas recebidas no programa. Nota-se claramente que o grupo dos alunos que não se submeteu à avaliação também se caracteriza por não ter recebido bolsa de auxílio ou ter recebido um número reduzido de bolsas. Pode-se observar que a maioria dos indivíduos que não participou das avaliações e recebeu bolsa permanece no programa por período máximo de 6 meses.

Gráfico 1 - Distribuição dos inscritos pelo número de auxilios financeiros.

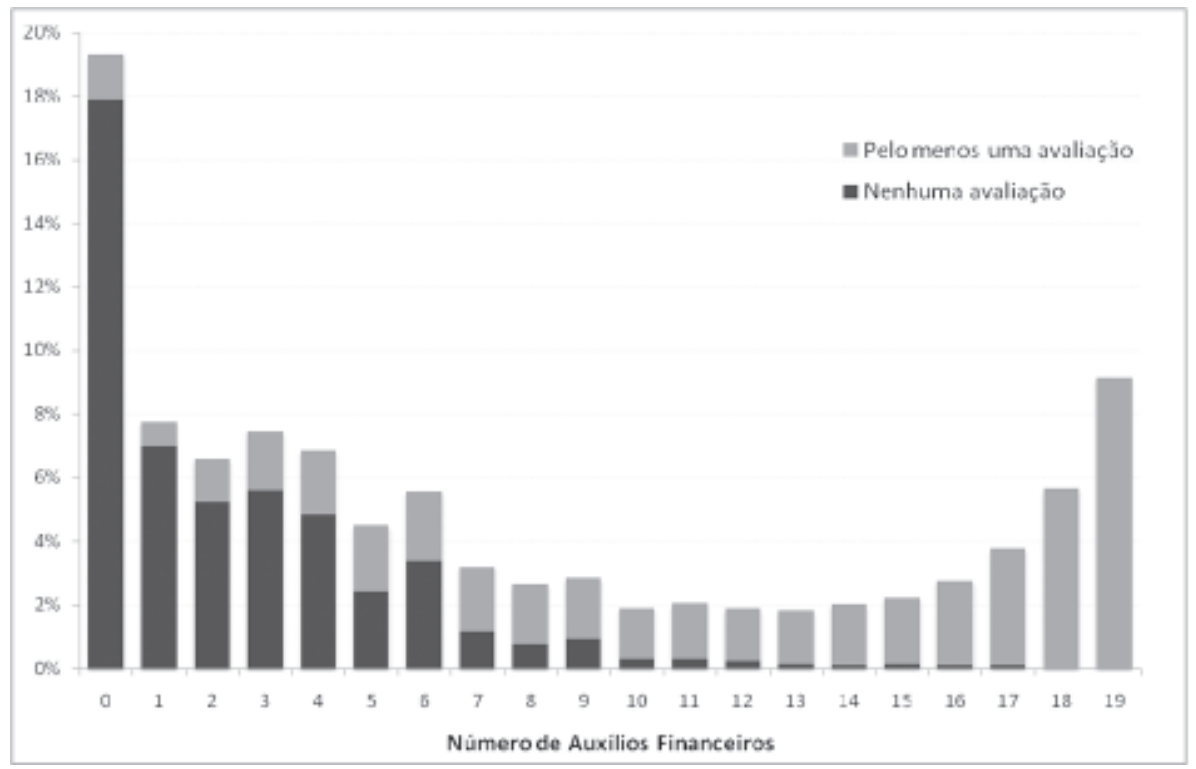

Fonte: ProJovem Urbano (2010).

Todas as análises produzidas neste trabalho têm como base os 47142 participantes. Quando se analisa a distribuição desses alunos por sexo, nota-se, imediatamente, que as mulheres são a maioria dos que efetivamente participaram do Programa. Considerando todos os casos, $45 \%$ são mulheres e $25 \%$ são homens; considerando os casos válidos, $65 \%$ são mulheres. Adicionalmente, o perfil predominante no Programa é o de indivíduos negros e pardos (50.4\% considerando todos os casos; $73 \%$ dos casos válidos). $\mathrm{Na}$ população brasileira de 15 a 29 anos, a percentagem de pretos e pardos é de 45.8\%.

Os gráficos 2 e 3 apresentam, respectivamente, a distribuição dos participantes por idade e pela última série frequentada. Considerando todos os casos, a distribuição por idade cai ligeiramente com o aumento da idade, parecendo situar-se em torno de 5\%. 0 
instrumento de recolha de dados não permite discriminar a distribuição da frequência pelas idades compreendidas entre 25 e 29 anos (Gráfico 2). Os alunos abandonaram o ensino fundamental em diferentes séries (Gráfico 3), o que sugere uma grande heterogeneidade nas proficiências à entrada do Programa e que é constatada nas medidas obtidas na avaliação diagnóstica, tal como se mostra adiante.

Gráfico 2 - Percentual dos alunos por idade.

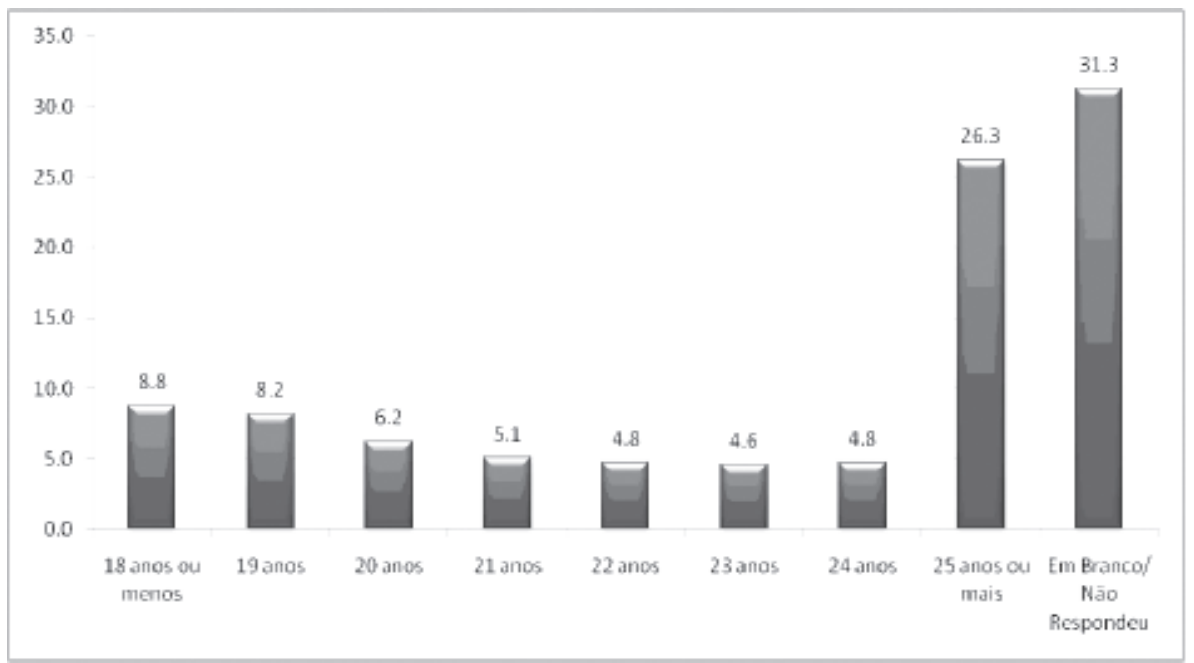

Fonte: ProJovem Urbano (2010).

Gráfico 3 - Percentual pela última série cursada.

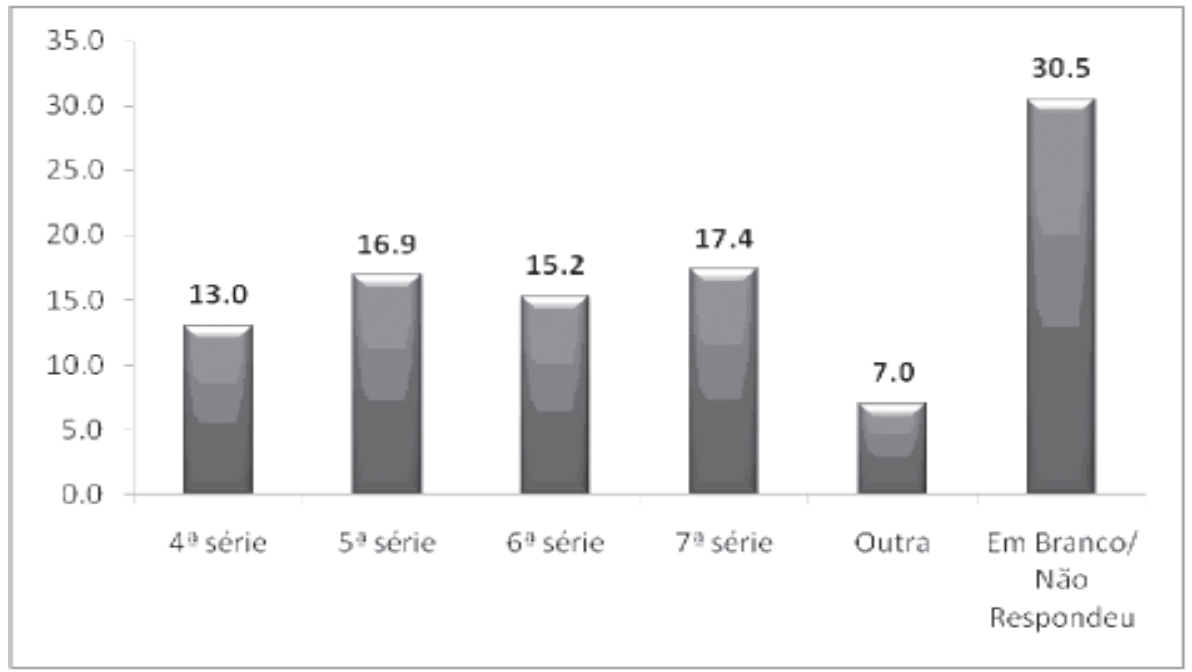

Fonte: ProJovem Urbano (2010). 


\section{Instrumentos e escalas de desempenho}

\section{Avaliação diagnóstica}

A primeira entrada de alunos do ProJovem Urbano ocorreu em setembro de 2008. No início de cada entrada, os alunos são submetidos a uma avaliação diagnóstica (AD) que afere o seu nível inicial de proficiência. Além dessa avaliação, os alunos realizam exames no final de cada ciclo formativo, sendo que o exame final de certificação corresponde à avaliação realizada no terceiro e último ciclo.

Os itens que compõem os testes do ProJovem Urbano passaram por um processo de calibração através de modelos de resposta ao item (TRI), de modo a permitir que os resultados dos exames desse programa sejam expressos nas mesmas escalas de proficiência do Sistema de Avaliação da Educação Básica (Saeb) ${ }^{4}$. Basicamente, o design do teste da avaliação diagnóstica foi o mesmo adotado pelo Saeb e todos os itens utilizados já tinham sido previamente calibrados utilizando-se os mesmos procedimentos do Saeb. Ao todo, foram utilizados 91 itens de Língua Portuguesa e 91 itens de Matemática distribuídos em cadernos de testes conforme o design apresentado na figura1.

Figura 1 - Design da avaliação diagnóstica.

\begin{tabular}{|c|c|c|c|c|c|c|c|c|c|}
\hline \multicolumn{5}{|c|}{ cadernos ímpares } & \multicolumn{5}{|c|}{ cadernos pares } \\
\hline \multirow{2}{*}{ caderno } & \multicolumn{4}{|c|}{ blocos } & \multirow{2}{*}{ caderno } & \multicolumn{4}{|c|}{ blocos } \\
\hline & Ip & mat & Ip & mat & & mat & Ip & mat & Ip \\
\hline 1 & 1 & 1 & 2 & 2 & 2 & 2 & 2 & 3 & 3 \\
\hline 3 & 3 & 3 & 4 & 4 & 4 & 4 & 4 & 5 & 5 \\
\hline 5 & 5 & 5 & 6 & 6 & 6 & 6 & 6 & 7 & 7 \\
\hline 7 & 7 & 7 & 1 & 1 & 8 & 1 & 1 & 3 & 3 \\
\hline 9 & 2 & 2 & 4 & 4 & 10 & 3 & 3 & 5 & 5 \\
\hline 11 & 4 & 4 & 6 & 6 & 12 & 5 & 5 & 7 & 7 \\
\hline 13 & 6 & 6 & 1 & 1 & 14 & 7 & 7 & 2 & 2 \\
\hline 15 & 1 & 1 & 4 & 4 & 16 & 2 & 2 & 5 & 5 \\
\hline 17 & 3 & 3 & 6 & 6 & 18 & 4 & 4 & 7 & 7 \\
\hline 19 & 5 & 5 & 1 & 1 & 20 & 6 & 6 & 2 & 2 \\
\hline 21 & 7 & 7 & 3 & 3 & & & & & \\
\hline
\end{tabular}

Fonte: Os autores (2010).

Nesse design, o mesmo que vem sendo adotado pelo Saeb a partir de 2007, os cadernos ímpares foram montados na ordem LP/MAT/LP/MAT e, nos cadernos pares, a ordem foi MAT/LP/MAT/LP. Nestes termos, a proficiência da avaliação diagnóstica está na escala do Saeb.

4 Para detalhes sobre esta classe de modelos estatísticos ver, por exemplo, Andrade, Tavares e Valle (2000). 


\section{Avaliação entre ciclos e certificação}

Cada um dos testes correspondentes aos ciclos 1 (C1) e 2 (C2), além do teste de certificação C3 (formas de teste C3.1 e C3.2) são constituídos por um único caderno para cada disciplina. Especificamente, para o ciclo 3 foi necessária a construção de duas formas do teste, sendo a segunda destinada aos alunos que faltaram à aplicação do primeiro teste de certificação final. Com o objetivo de ligar a escala de cada um destes testes à escala do Saeb, construíram-se dois testes de calibração (TC1, TC2). Os testes de calibração são compostos por todos os itens dos testes C1, C2 e C3 e por itens do Saeb 2003, e foram aplicados a uma amostra representativa dos alunos da 8 a série do Ensino Fundamental (população de referência do Saeb).

Após a aplicação dos testes de calibração, foram realizados os procedimentos de equalização para a escala Saeb, através do método de equalização descrito por Klein (2003). Tendo sido calibrados todos os itens na escala do Saeb, as proficiências foram então produzidas para todos os alunos que responderam aos testes $\mathrm{C}_{1}, \mathrm{C} 2$, C3. Assim, os resultados alcançados pelos alunos do ProJovem Urbano, na avaliação diagnóstica e nas avaliações entre os ciclos, foram produzidos na escala do Saeb, tal como foi exposto acima. A escala varia de 0 a 500 pontos e propicia a interpretação das habilidades e competências desenvolvidas pelos alunos avaliados em Língua Portuguesa e em Matemática ao longo da Educação Básica.

No Diagrama 1 são descritas as etapas que se verificaram no processo de calibração.

Diagrama 1 - Esquema do processo de calibração.

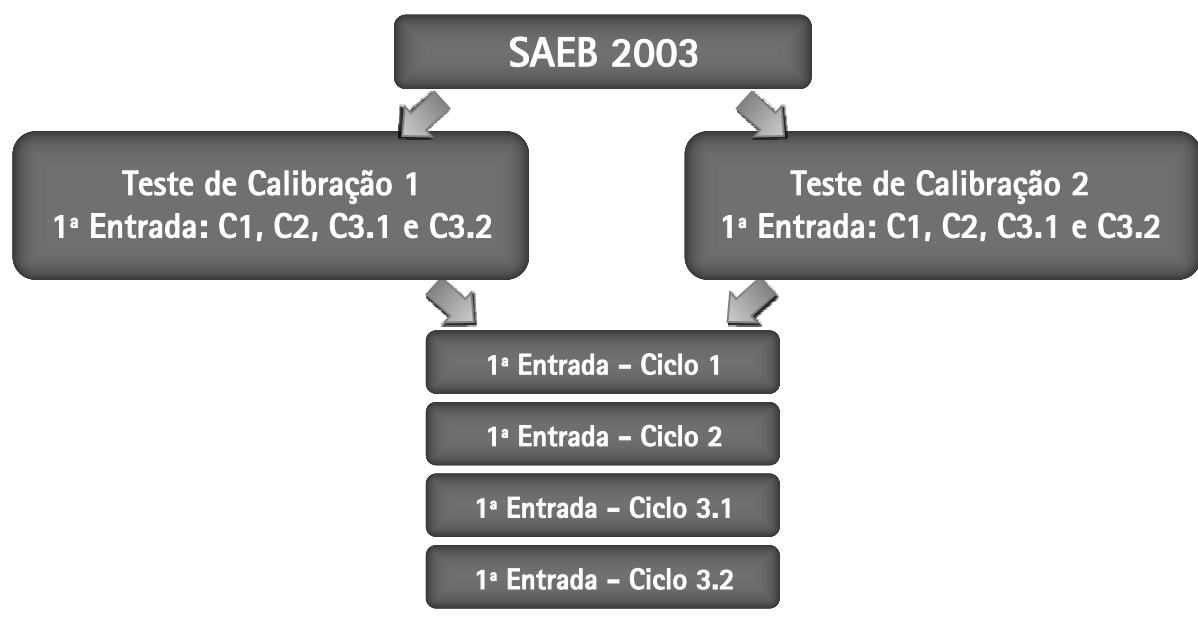

Fonte: Os autores (2010). 
A Tabela 2 apresenta o número de participantes em cada uma das etapas de avaliação.

Tabela 2: Número efetivo de jovens avaliados na $1^{\text {a }}$ entrada para cada etapa de avaliação.

\begin{tabular}{l|c|c|c|c|c}
\hline \multirow{2}{*}{ Disciplina } & \multirow{2}{*}{ AD } & \multirow{2}{*}{ Ciclo 1 } & \multirow{2}{*}{ Ciclo 2 } & \multicolumn{2}{|c}{ Ciclo 3 } \\
\cline { 4 - 6 } & & & & C1 & C2 \\
\hline Língua Portuguesa & 33621 & 34877 & 27141 & 20881 & 4313 \\
\hline Matemática & 32078 & 34877 & 27141 & 20881 & 4313 \\
\hline
\end{tabular}

Fonte: Os autores (2010).

\section{Modelo de regressão logística multinível}

0 modelo estatístico usado para a modelagem da evasão é um modelo multinível, de dois níveis, que pertence à classe dos modelos lineares generalizados com função de ligação logit (MCCULLAGH; NELDER, 1989, p. 107). Nestes termos, aplicou-se o modelo de regressão logística multinível (GOLDSTEIN, 2003, p. 97), considerando alunos agrupados em centros de formação. 0 aluno é a unidade do nível um (índice i) e o centro a unidade do nível dois (índice j).

A variável resposta, Y, representa a situação do aluno face à evasão. É uma variável binária com valor 1 se o aluno se evadiu e 0 em caso contrário. As variáveis explicativas consideradas nos termos aditivos do preditor linear são: faixa etária (18 a 20 anos; 21 a 24 anos; 25 anos ou mais), sexo (1: masculino; 0: feminino), raça/cor, proxy para condição econômica (1: mãe sabe escrever; 0: mãe não sabe escrever), última série frequentada, nível de conhecimento à entrada do Programa (aferido pelo respectivo quartil da avaliação diagnóstica em Matemática), região metropolitana (Sul, Sudeste II, Sudeste III, Nordeste I, Nordeste II, Nordeste III, Centro-Oeste). Para maiores detalhes sobre a especificação do modelo estatístico, pressupostos do modelo e procedimentos de estimação sugere-se a leitura de Goldstein (2003).

\section{Resultados}

\section{Aprovação/reprovação/evasão e comparação do desempenho}

Considerando o número de participantes no Programa, 47.142 indivíduos, o número de alunos que evadiram é bastante elevado (19199, cerca de 41\%). Os reprovados representam 26\% e, portanto, apenas 33\% (15424) dos alunos foram aprovados (Gráfico 4). 
Gráfico 4 - Percentual de aprovação, reprovação e evasão.

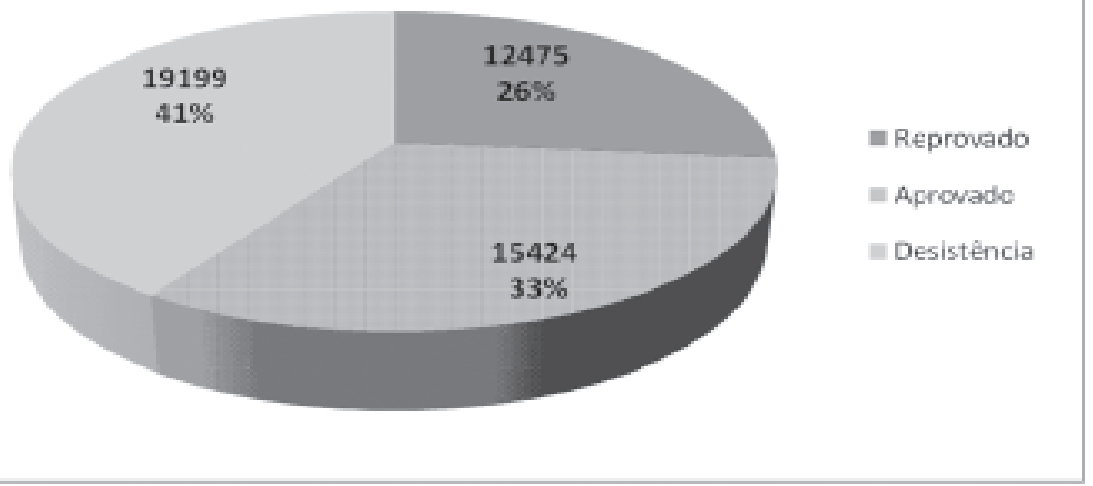

Fonte: Os autores (2010).

A análise da média de proficiência dos mesmos alunos na avaliação diagnóstica e no exame de certificação permite observar o crescimento em termos das aprendizagens realizadas, mesmo para os alunos que foram reprovados no programa (Gráficos 5 e 6). Esse fato sugere que, embora os alunos reprovados não tenham alcançado o mínimo necessário para obterem o certificado de conclusão do Ensino Fundamental, eles foram beneficiados pelo Programa. Para comparação, note-se que a proficiência média dos alunos da $8^{a}$ série do ensino fundamental que participaram do SAEB 2005 foi de 231.9 pontos em Língua Portuguesa e 239.5 pontos em Matemática (INEP, 2007).

Gráfico 5 - Comparação da média de proficiência da AD e do Exame de Certificação: Língua Portuguesa.

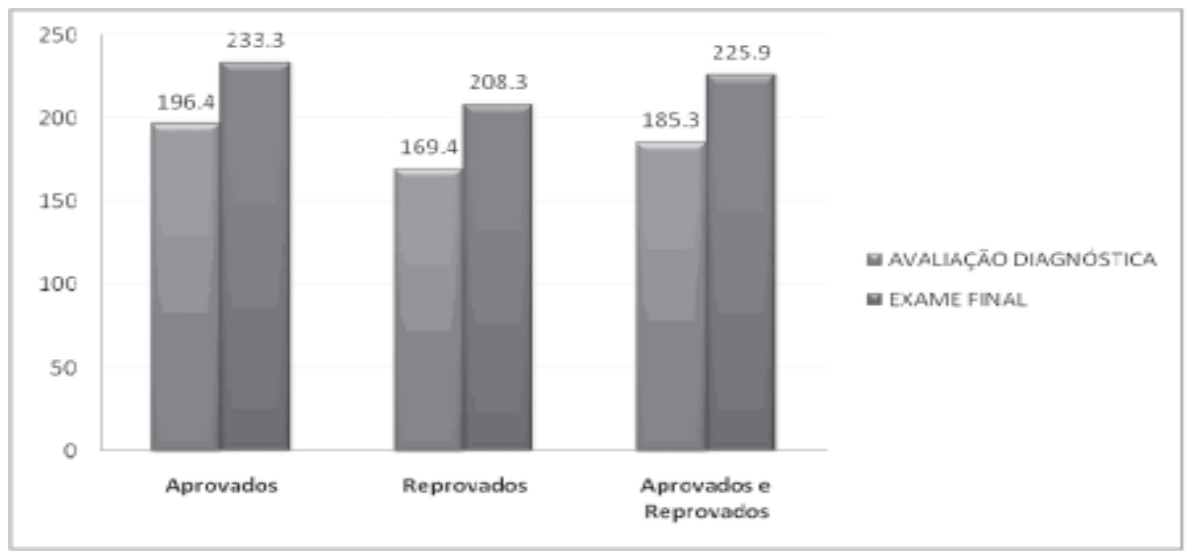

Fonte: Os autores (2010). 
Gráfico 6 - Comparação da média da proficiência da AD e do Exame de Certificação: Matemática.

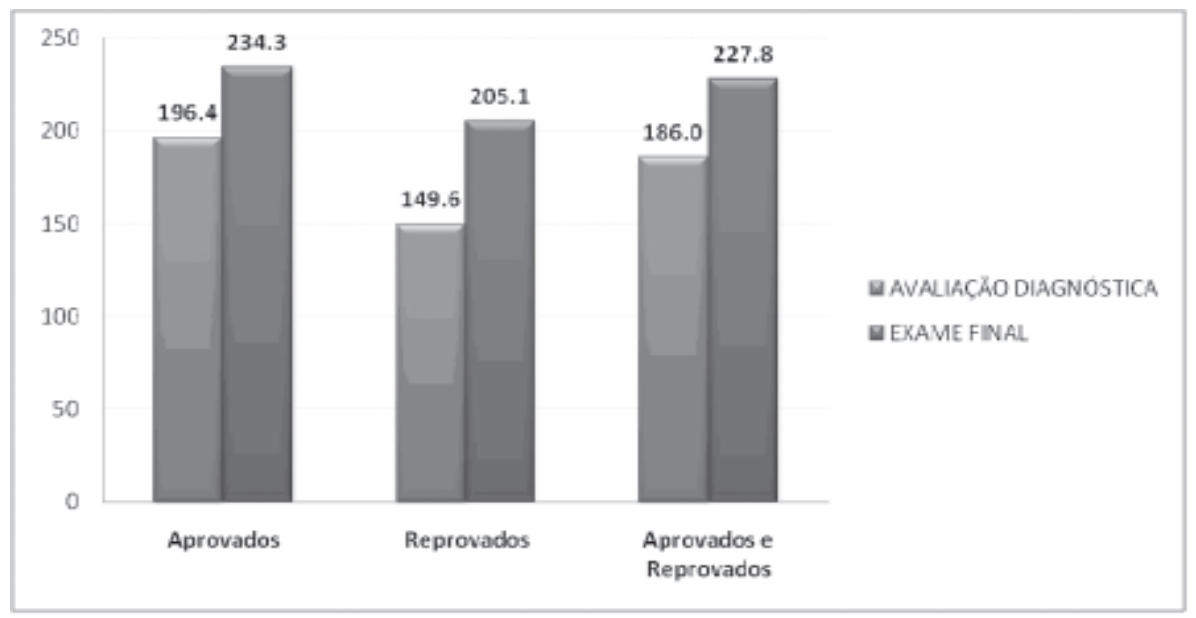

Fonte: Os autores (2010).

\section{Comparação regional do desempenho no programa}

Comparando o desempenho dos alunos na avaliação diagnóstica com o desempenho no exame de certificação, observa-se claramente o crescimento da proficiência em todas as regiões (Gráficos 7 a 10). 0 código de cada coordenação regional é como segue: 386 Sudeste II, 387 Nordeste I, 388 Sul, 405 Centro-Oeste, 488 Nordeste II, 854 Nordeste III, 519 Norte I, 1919 Sudeste III.

Gráfico 7 - Média da proficiência por Região no início do Programa: Matemática.

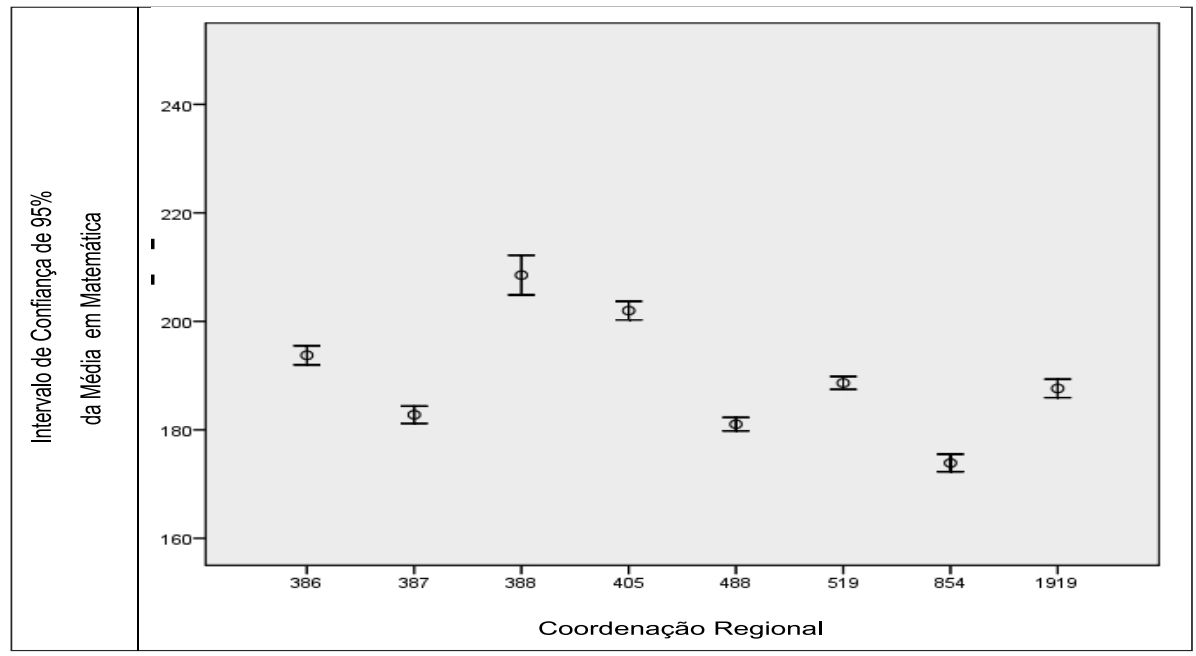

Fonte: Os autores (2010). 
Gráfico 8 - Média da proficiência por Região no final do Programa: Matemática.

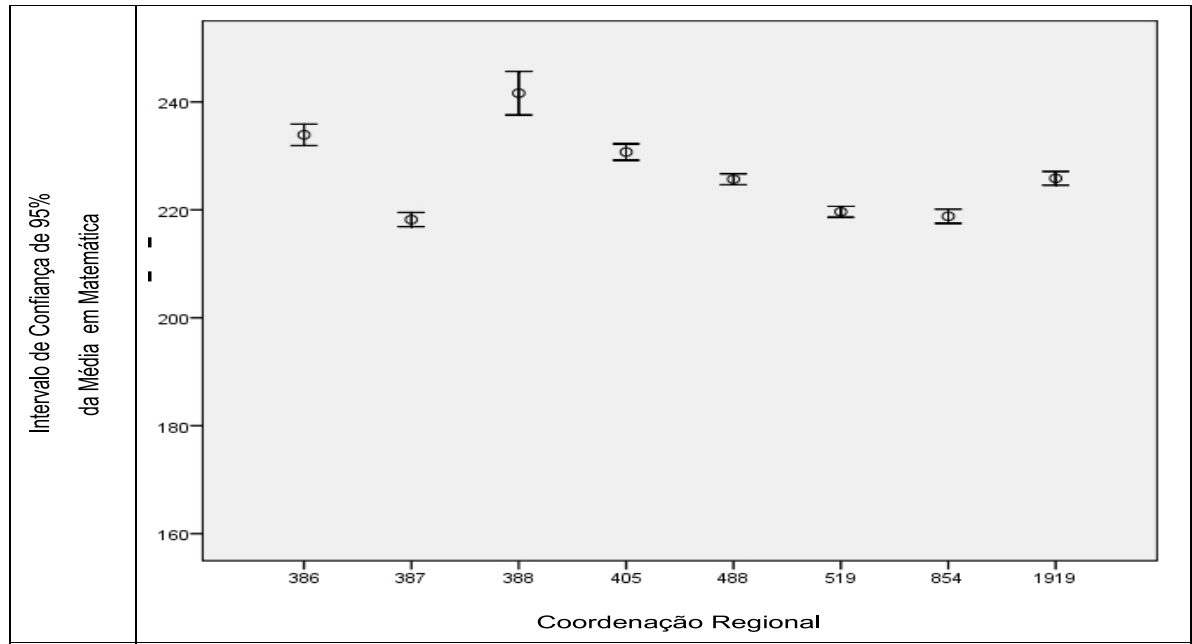

Fonte: Os autores (2010).

Gráfico 9 - Média da proficiência por Região no início do Programa: Língua Portuguesa.

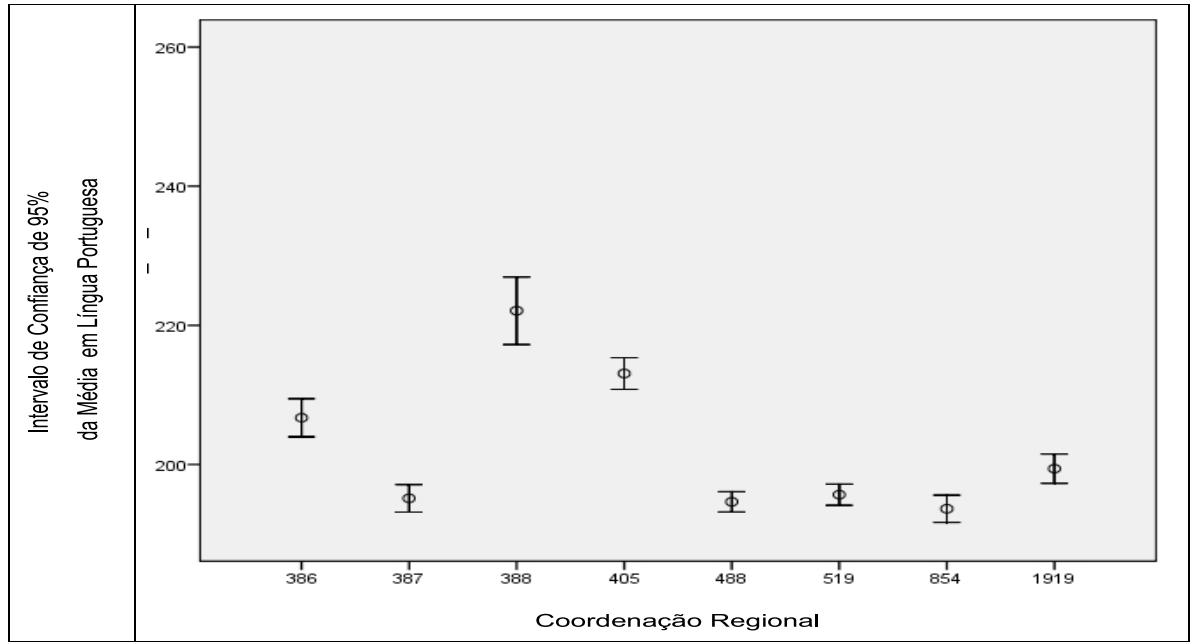

Fonte: Os autores (2010). 
Gráfico 10 - Média da proficiência por Região no final do Programa: Língua Portuguesa.

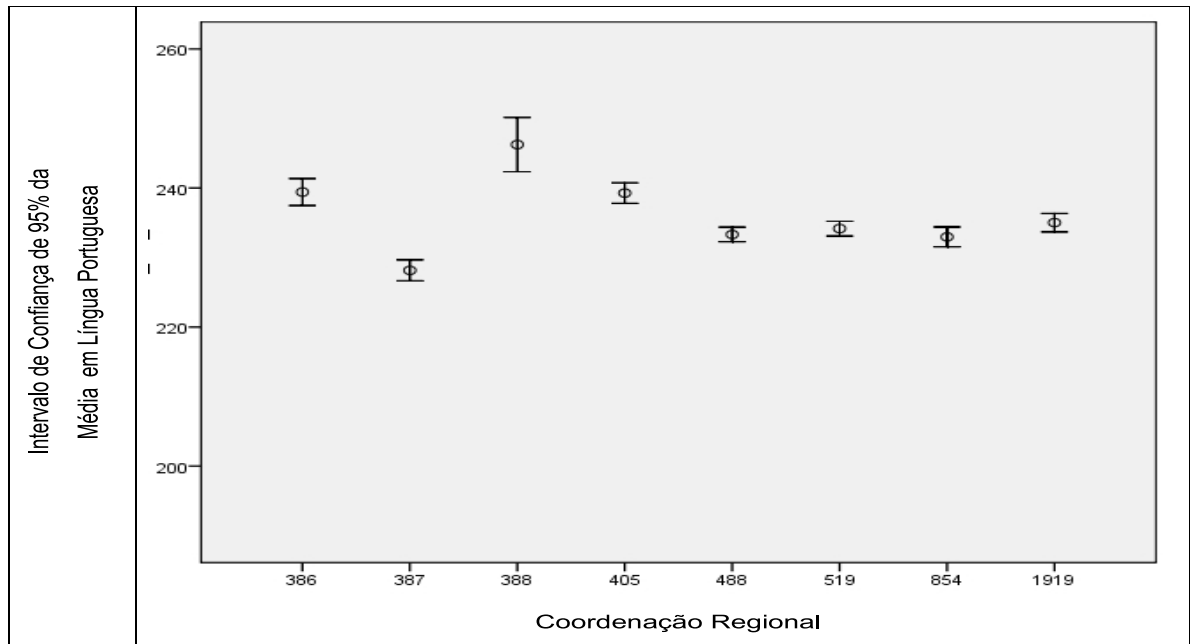

Fonte: Os autores (2010).

A análise dos Gráficos 7 a 10 sugere ainda que o Programa promoveu a redução de diferenças regionais no que se refere ao conhecimento em Matemática (Gráfico 7 e 8) e Língua Portuguesa (Gráfico 9 e 10). Por exemplo, é interessante notar que a região de código 854 (coordenação regional Nordeste III), que apresentava média de desempenho inferior a todas as demais na AD de Matemática (Gráfico 7), conseguiu igualar outras regionais no respectivo exame de certificação final (Gráfico 8).

\section{Fatores associados à evasão}

0 modelo de regressão logística multinivel descrito na subsecção 2.3 foi aplicado aos dados dos alunos que constituem o $1^{\circ}$ coorte do ProJovem Urbano. Na análise de dados os valores omissos foram considerados completamente aleatórios, na designação anglo-saxónica missing completely at random (LITTLE; RUBIN, 1987). A Tabela 3 contém o odds ratio calculado para as variáveis explicativas e tendo por base 0 ajuste do modelo separadamente com diferentes conjuntos de variáveis. Deste modo, na coluna [1] apresentam-se os resultados obtidos para as variáveis sexo, faixa etária, raça-cor, última série frequentada e nível socioeconômico. Pode observar-se que o odds ratio da evasão por sexo é 1.5, ou seja, para cada duas alunas que se evadem do curso há três alunos a fazê-lo. As estimativas obtidas também sugerem que há um padrão na evasão que está associado à idade. Observe-se que o odds ratio é maior quanto menor a faixa etária, sugerindo que se verifica maior evasão entre os mais jovens comparativamente com o grupo dos alunos com 25 anos ou mais. No que concerne às demais variáveis cujos resultados se apresentam na coluna [1] não há evidência de relação estatisticamente significativa com a probabilidade de evasão. 
Na coluna [2] apresenta-se o resultado do odds ratio calculado para a variável que representa o nivel de conhecimento em Matemática do aluno ingressado, com base nos quartis da avaliação diagnóstica (controlando por faixa etária e sexo). Verifica-se que o fato do aluno à entrada no Programa mostrar desempenho ao nível do $2^{\circ}, 3^{\circ}$ ou mesmo $4^{\circ}$ quartil da distribuição da proficiência, não tem efeito estatisticamente significativo na probabilidade de evasão. Já no que se refere à região metropolitana onde o aluno vive, os resultados sugerem que a probabilidade do aluno se evadir na região Sudeste II é 5.5 vezes maior comparativamente com o que acontece na região Nordeste II (controlando por faixa etária e sexo). A mesma relação é quantificada em 2.8 no Sul, 2.7 no Centro-Oeste, 2.2 no Nordeste I, 2.0 no Norte I, 1.9 no Sudeste III e 1.8 no Nordeste III.

A Tabela 4 contém as estimativas e respectivo erro padrão do modelo de regressão logística ajustado com as variáveis cujos parâmetros são estatisticamente diferentes de zero. A interpretação destes resultados corresponde à que foi realizada acima, com base nos odds ratio apresentados na coluna [3] da Tabela 3.

Tabela 3 - Odds Ratio de Evasão no ProJovem Urbano.

\begin{tabular}{|c|c|c|c|}
\hline Variáveis & Odds Ratio[1] & Odds Ratio [2] & Odds Ratio [3] \\
\hline Masculino/Feminino & 1.5 & 1.5 & 1.5 \\
\hline Idade: $18-20 / 25+$ & 1.6 & 1.6 & 1.6 \\
\hline Idade: $21-24 / 25+$ & 1.4 & 1.4 & 1.4 \\
\hline Raça-Cor: Pardo/Branco & 1.1 & -- & -- \\
\hline Raça-Cor: Negro/Branco & 1.1 & -- & -- \\
\hline Raça-Cor: Amarelo/Branco & 1.1 & -- & -- \\
\hline Raça-Cor: Indígena/Branco & 1.0 & -- & -- \\
\hline Última série: $5^{\text {as }} / 4^{\text {as }}$ & 1.0 & -- & -- \\
\hline Última série: $6^{\mathrm{a}} \mathrm{s} / 4^{\mathrm{a}} \mathrm{s}$ & 0.9 & -- & -- \\
\hline Última série: 7as $/ 4^{\mathrm{a}} \mathrm{s}$ & 0.9 & -- & -- \\
\hline Última série: outra/4as & 1.0 & -- & -- \\
\hline Mãe sabe escrever: Sim/Não & 1.1 & -- & -- \\
\hline Mãe sabe escrever: Não_sei/Não & 0.9 & -- & -- \\
\hline Quartis_AD(matemática):02/01 & -- & 1.0 & -- \\
\hline Quartis_AD(matemática):03/01 & -- & 1.1 & -- \\
\hline Quartis_AD(matemática):04/01 & -- & 1.1 & -- \\
\hline Região: SDII/NDII & -- & -- & 5.5 \\
\hline Região: NDI/NDII & -- & -- & 2.2 \\
\hline Região: Sul/NDII & -- & -- & 2.8 \\
\hline Região: C-0/NDII & -- & -- & 2.7 \\
\hline Região: NI/NDII & -- & -- & 2.0 \\
\hline Região: NDIII/NDII & -- & -- & 1.8 \\
\hline Região: SDIII/NDII & -- & -- & 1.9 \\
\hline
\end{tabular}

Fonte: Os autores (2010). 
Adicionalmente, há evidência de variabilidade na probabilidade de evasão entre centros de formação, mesmo quando a região metropolitana é levada em consideração no modelo. 0 parâmetro aleatório associado ao nível 2, centro de formação, é 0.113 com erro padrão 0.032 . Estas estimativas sugerem que há características associadas aos centros (ou sua envolvente) que conduzem a probabilidades diferenciadas na evasão dos alunos.

Tabela 4 - Estimativas do Modelo Logístico Multinível para evasão.

\begin{tabular}{c|c|c}
\hline Variáveis & Estimativa do Parâmetro Fixo & Erro Padrão \\
\hline Constante & -1.50 & 0.168 \\
\hline Masculino/Feminino & 0.391 & $<0.001$ \\
\hline Idade: $18-20 / 25+$ & 0.498 & $<0.001$ \\
\hline Idade: $21-24 / 25+$ & 0.346 & $<0.001$ \\
\hline Região: SDII/NDII & 1.701 & 0.217 \\
\hline Região: NDI/NDII & 0.803 & 0.257 \\
\hline Região: Sul/NDII & 1.045 & 0.376 \\
\hline Região: C-O/NDII & 1.012 & 0.291 \\
\hline Região: NI/NDII & 0.708 & 0.258 \\
\hline Região: NDIII/NDII & 0.568 & 0.257 \\
\hline Região: SDIII/NDII & 0.618 & 0.257
\end{tabular}

Fonte: Os autores (2010).

\section{Observações finais}

0 artigo aborda aspectos da avaliação do Programa ProJovem Urbano (2010), com base na análise e modelagem dos dados do $1^{\circ}$ coorte, no que concerne à quantificação da desistência e evasão, à identificação de grupos de maior incidência da evasão e também à avaliação do desempenho do programa no que se refere às aprendizagens em Matemática e Língua Portuguesa realizadas pelos alunos que concluíram o Programa. A aferição das aprendizagens foi realizada através da aplicação de instrumentos calibrados na escala do Saeb.

0 ProJovem Urbano é um Programa desenhado para fomentar a inclusão social dos jovens brasileiros de 18 a 29 anos que, apesar de alfabetizados, não concluíram o ensino fundamental.

0 número de indivíduos que manifestaram interesse no Programa foi 95037. Destes, aproximadamente metade desistiu de participar efetivamente. A desistência pode ter ocorrido num período que chega a ser superior a seis meses. Durante esse período, esses indivíduos não se submeteram a qualquer avaliação das aprendizagens em Matemática ou Língua Portuguesa, prenúncio de eventual desistência, apesar de continuarem a receber bolsa, representando um desperdício do Programa. 
Dos 47142 participantes efetivos, 65\% são do sexo feminino, 73\% são negros ou pardos e 38\% com idade compreendida entre 25 e 29 anos (considerando os casos válidos). É, portanto, relevante assinalar a elevada participação de indivíduos do sexo feminino e também os de raça/cor preto e pardo se considerarmos a distribuição da população brasileira por sexo e raça/cor. A predominância das participação feminina é a repetição do que habitualmente se vem observando no sistema de educação formal. Nesse caso, essa disparidade é ainda mais acentuada, pois na população alvo do Programa há mais homens, já que a evasão é mais acentuada entre indivíduos do sexo masculino no sistema de educação formal. No que se refere a raça/cor, a configuração do Programa previa a maior participação de cidadãos de raça/cor preto ou pardo. Estes grupos estão associados a menor nível de instrução, pobreza e com menor probabilidade de ter ocupação valorizada (SCHWARTZMAN, 2000).

Entre os participantes, 33\% foram aprovados, 26\% reprovados e $41 \%$ evadidos. A análise da proficiência em Matemática e Língua Portuguesa dos concluintes mostra que todos eles beneficiaram, de algum modo, do Programa. Em Língua Portuguesa, os alunos aprovados obtiveram 233.3 pontos no exame final (e na avaliação diagnóstica 196.4) enquanto os reprovados obtiveram 208.3 pontos (e na avaliação diagnóstica 169.4). Em Matemática, os alunos aprovados obtiveram 234.3 pontos no exame final (e na avaliação diagnóstica 196.4) enquanto os reprovados obtiveram 205.1 pontos (e na avaliação diagnóstica 149.6). Para efeito de comparação, a proficiência média dos alunos da $8^{\mathrm{a}}$ série do Ensino Fundamental que participaram do Saeb 2005, foi de 231.9 em Língua Portuguesa e 239.5 em Matemática. Embora não tenham alcançado o mínimo necessário para obter o certificado de conclusão do Ensino Fundamental, mesmo os alunos reprovados foram beneficiados pelo Programa. Considerando a percentagem dos alunos que, apesar de reprovados, obtiveram classificação final compreendida entre a média e a classificação final mínima para aprovação/certificação, deveria ser equacionado um programa especial de formação orientado a esses alunos para colmatar o déficit de aproveitamento e evitar que eles precisem repetir todo o programa para obter a certificação. Adicionalmente, verificou-se que a heterogeneidade regional do conhecimento em Matemática e Língua Portuguesa diminuiu com a implementação do Programa na população alvo.

Através da aplicação do modelo de regressão logística multinivel foram identificados os grupos de maior incidência da evasão. Eles diferenciam-se pela idade - em geral o participantes mais jovens apresentam maior probabilidade de evasão; por sexo, os homens evadem-se do programa 1.5 vezes mais do que as mulheres; e por região. As estimativas do modelo sugerem a existência de efeito não estatisticamente significativo na relação entre evasão e as variáveis raça/cor, última série frequentada, nivel de conhecimento à entrada no programa e nivel socioeconômico (proxy"mãe sabe escrever"). 
A limitação dos resultados apresentados assenta, fundamentalmente, no elevado número de dados em falta (em torno de $30 \%$ ). As análises efetuadas foram por nós consideradas completamente aleatórias. Decorre a recomendação de melhoria no protocolo de aplicação dos questionários de recolha de dados e posterior reanálise dos dados referentes aos coortes seguintes para efeito confirmatório.

Em síntese, há duas grandes conclusões no estudo de avaliação do Programa apresentado neste trabalho. Uma positiva e outra negativa. A primeira é que todos os alunos concluintes, certificados ou não, melhoraram o nível de proficiência em Matemática e Língua Portuguesa. A segunda é a constatação da excessiva taxa de desistência e evasão do Programa, requerendo medidas adicionais para o evitar. Já que ao longo do trabalho foram identificados os grupos de maior incidência da evasão, são necessárias medidas específicas que visem à retenção no programa dos participantes mais do sexo masculino. No entanto, estudos adicionais fazem-se necessários para compreender melhor o fenômeno da desistência e evasão, em particular procurar a explicação das diferenças regionais verificadas.

Numa perspectiva de avaliação holística do Programa, seria conveniente proceder-se ao estudo de follow-up dos alunos certificados de modo a verificar se o grande desígnio do ProJovem Urbano - inclusão social - está sendo alcançado.

\section{Agradecimentos}

Os autores agradecem as valiosas sugestões e comentários dos pareceristas anônimos.

\section{Referências}

ANDRADE, D. F.; TAVARES, H. R.; VALLE, R. C. Teoria da Resposta ao Item: conceitos e aplicações. São Paulo: Associação Brasileira de Estatística, 2000.

BRASIL. Decreto $\mathrm{n}^{\circ}$ 6.628, de 4 de novembro de 2008. Aprova o Estatuto do Fundo Garantidor de Financiamentos - FGF, de que trata o art. $4^{\circ}$ da Lei $n^{0} 11.524$, de 24 de setembro de 2007. Diário Oficial da União, Brasília, DF, 5 nov. 2008a.

. Decreto-Lei ${ }^{\circ}$ 6629, de 4 de novembro de 2008. Regulamenta o Programa Nacional de Inclusão de Jovens - Projovem, instituído pela Lei $n^{0}$ 11.129 , de 30 de junho de 2005, e regido pela Lei $n^{0} 11.692$, de 10 de junho de 2008, e dá outras providências. Diário Oficial da União, Brasília, DF, 5 nov. 2008 b.

BRASIL. Lei $n^{\circ}$. 9.394, de 20 de dezembro de 1996. Estabelece as diretrizes e bases da educação nacional. Diário Oficial [da] Republica Federativa do Brasil, Brasília, DF, 23 dez. 1996. 
BRASIL. Lei no 11.129, de 30 de junho de 2005. Institui o Programa Nacional de Inclusão de Jovens - ProJovem; cria o Conselho Nacional da Juventude - CNJ e a Secretaria Nacional de Juventude; altera as Leis $n^{\circ} \mathrm{s} 10.683$, de 28 de maio de 2003, e 10.429, de 24 de abril de 2002; e dá outras providências. Diário Oficial da União, Brasília, DF, 1 jul. 2005.

. Lei $n^{\circ} 11.692$, de 10 de junho de 2008. Dispõe sobre o Programa Nacional de Inclusão de Jovens - Projovem, instituído pela Lei ${ }^{\circ} 11.129$, de 30 de junho de 2005; altera a Lei $\mathrm{n}^{\circ} 10.836$, de 9 de janeiro de 2004; revoga dispositivos das Leis $\mathrm{n}^{\text {os }}$ 9.608, de 18 de fevereiro de 1998, 10.748, de 22 de outubro de 2003, 10.940, de 27 de agosto de 2004, 11.129, de 30 de junho de 2005, e 11.180, de 23 de setembro de 2005; e dá outras providências. Diário Oficial da União, Brasília, DF, 11 jun. 2008c.

Secretaria-Geral da Presidência da República. Coordenação Nacional do ProJovem. Relatório parcial de avaliação do ProJovem 2007. Brasília, DF, 2008d.

GOLDSTEIN, H. Multilevel Statistical Models. 3. ed. London: Edward Arnold, 2003.

IBGE. Pesquisa Nacional por Amostra de Domicílios 2008. Rio de Janeiro, 2009

INEP. Saeb 2005: primeiros resultados: médias de desempenho do SAEB/2005 em perspectiva comparada. Brasília, DF, 2007.

KLEIN, R. Utilização da Teoria de Resposta ao Item no Sistema Nacional de Avaliação da Educacção Básica (Saeb). Ensaio: avaliação e políticas públicas em Educação, Rio de Janeiro, v. 11, n. 40, p. 283-296, jul./set. 2003.

Como está a educação no Brasil? o que fazer?. Ensaio: avaliação e políticas públicas em Educação, Rio de Janeiro, v. 14, n. 51, p. 139-172, abr./jun. 2006.

LITTLE, R. J. A.; RUBIN, D.B. Statistical analysis with Missing Data. New York: Wiley, 1987.

MC CULLAGH, P.; NELDER, J. A. Generalized Linear Models. 2. ed. Boca Raton, Florida: Chapman \& Hall, 1989.

OECD. Directorate for Education. Education at a Glance 2010: OECD Indicators. Paris, 2010. Disponivel em: <http://www.oecd.org/document/52/0,3746,en_ 2649_39263238_45897844_1_1_1_1,00.html>. A cesso em: 25 out. 2011. 
PROJOVEM Urbano. Finalidade. Brasilia, DF, 2010. Disponivel em: <http:// www.projovemurbano.gov.br/site/

interna.php? $p=$ material\&tipo=Conteudos\&tcod=14>. Acesso em: 21 out. 2011.

SCHWARTZMAN, S. Brazil: the social agenda. Daedalus, Cambridge, MA, p. 2955, Spring 2000. Disponivel em: <http://www.schwartzman.org.br/simon/ daedalus.htm>. Acesso em: 21 out. 2011.

Recebido em: 30/11/2010

Aceito para publicação em: 30/08/2011 